\title{
RESEARCH
}

\section{When patients have to pay a share of drug costs: effects on frequency of physician visits, hospital admissions and filling of prescriptions}

\author{
Aslam H. Anis, Daphne P. Guh, Diane Lacaille, Carlo A. Marra, Amir A. Rashidi, Xin Li, John M. Esdaile
}

An abridged version of this article appeared in the Nov. 22, 2005, issue of CMAJ.

\section{ABSTRACT}

Background: Previous research has shown that patient costsharing leads to a reduction in overall health resource utilization. However, in Canada, where health care is provided free of charge except for prescription drugs, the converse may be true. We investigated the effect of prescription drug cost-sharing on overall health care utilization among elderly patients with rheumatoid arthritis.

Methods: Elderly patients ( $\sigma_{5}$ years) were selected from a population-based cohort with rheumatoid arthritis. Those who had paid the maximum amount of dispensing fees (\$200) for the calendar year (from 1997 to 2000) were included in the analysis for that year. We defined the period during which the annual maximum co-payment had not been reached as the "cost-sharing period" and the one beyond which the annual maximum co-papyment had been reached as the "free period." We compared health services utilization patterns between these periods during the 4 study years, including the number of hospital admissions, the number of physician visits, the number of prescriptions filled and the number of prescriptions per physician visit.

Results: Overall, 2968 elderly patients reached the annual maximum cost-sharing amount at least once during the study periods. Across the 4 years, there were 0.38 more physician visits per month $(p<0.001), 0.50$ fewer prescriptions filled per month $(p=0.001)$ and 0.52 fewer prescriptions filled per physician visit $(p<0.001)$ during the costsharing period than during the free period. Among patients who were admitted to the hospital at least once, there were 0.013 more admissions per month during the cost-sharing period than during the free period $(p=0.03)$.

Interpretation: In a predominantly publicly funded health care system, the implementation of cost-containment policies such as prescription drug cost-sharing may have the unintended effect of increasing overall health utilization among elderly patients with rheumatoid arthritis.

Cite this article as $C M A J$ 2005;I73(II). DOI:I0.I503/cmaj.045I46
$\mathrm{T}$ o accommodate continually rising prescription drug costs, various cost-containment policies have been implemented. One such policy, cost-sharing between patients and insurers, is common in developed countries. In addition to shifting expenditures from insurers (often governments) to consumers, this financing mechanism is appealing because it supposedly reduces expenditures for medically unnecessary treatments by making patients pay for a proportion of all expenditures and thus making them more cost-conscious.

The RAND Health Insurance Experiment was the first scientifically rigorous study that established the impact of costsharing for medical services. ${ }^{1}$ Interim results showed that the total cost of health care for participants who received free care was $38 \%$ higher than that for families who paid for part of their care. ${ }^{2}$ On completion of the RAND study, there was strong evidence to suggest that ill patients were less likely to seek treatment or be admitted to hospital if they had to pay a portion of the cost.1,3,4

The most comprehensive, recent study to examine the impact of cost-sharing specifically of prescription drugs investigated various employer drug-benefit plans and prescription drug spending. ${ }^{5}$ Beneficiaries of the plans with higher copayments used less medication and less expensive drugs than those with lower co-payments, and although overall costs for insurers fell, the beneficiaries' out-of-pocket drug expenses rose significantly. In a managed-care setting, studies have shown that cost-sharing was associated with reduced expenditures for prescription drugs and for physician services and outpatient hospital services. ${ }^{6-8}$ The results of these studies suggested that prescription drugs and other health services were "complementary" goods. (Goods or services are considered to be "complementary" when the increase or decrease in the price of one of the goods or services leads to a corresponding decrease or increase in the consumption of the other. In contrast, goods and services are defined as economic substitutes if the quantity demanded of one rises or falls when the price of the other rises or falls.)

In Canada, where most treatments and health services are covered by the government and user fees are prohibited, a 
predominantly publicly funded health care system with firstdollar coverage (no deductible or co-payment) exists. One gaping hole in the Canadian health care coverage blanket is that outpatient drugs are not available free of charge to all people. At present, outpatient drug coverage varies considerably; for example, people on social assistance usually do not have to pay for their prescription drugs. The overall impact of having incomplete coverage for drugs remains unknown. ${ }^{9}$

We conducted this study to investigate the impact of outpatient prescription drug cost-sharing on the overall utilization of health care services. Because the decision to choose a drug therapy over another intervention is a complex process that is influenced by a host of clinical and socioeconomic factors, we chose to focus our investigation on rheumatoid arthritis, a chronic, disabling condition for which pharmacotherapy remains the mainstay of treatment. Our hypothesis was that, in the Canadian context, people who have to pay for outpatient drugs might decrease their drug use and instead rely on free types of care such as in-hospital drug therapy or physician visits; thus, patient cost-sharing of drugs might increase the overall demand for health care services.

\section{Methods}

A population-based cohort of people with rheumatoid arthritis in British Columbia was selected in 2002. Administrative

Table 1: Characteristics of 2968 patients with existing rheumatoid arthritis who reached the annual maximum co-payment at least once during the study period*

\begin{tabular}{|c|c|c|c|c|}
\hline Characteristic & $\begin{array}{c}1997 \\
n=6476\end{array}$ & $\begin{array}{c}1998 \\
n=7593\end{array}$ & $\begin{array}{c}1999 \\
n=8530\end{array}$ & $\begin{array}{c}2000 \\
n=9351\end{array}$ \\
\hline $\begin{array}{l}\text { Reached maximum } \\
\text { co-payment, no. (\%) }\end{array}$ & $1191(18.4)$ & $1428(18.8)$ & $1702(20.0)$ & $1882(20.1)$ \\
\hline Age, mean (SD), yr & $74.0(6.3)$ & $74.2(6.2)$ & $74.8(6.4)$ & $75.1(6.6)$ \\
\hline Female, \% & 78 & 77 & 75 & 76 \\
\hline $\begin{array}{l}\text { Disease duration (left- } \\
\text { censored at 1990), mean } \\
\text { (SD), yr }\end{array}$ & $4.4(2.3)$ & $4.8(2.7)$ & $5.3(3.0)$ & $5.8(3.2)$ \\
\hline \multicolumn{5}{|l|}{ Used DMARDs $†$} \\
\hline Yes, \% & 45 & 47 & 49 & 49 \\
\hline $\begin{array}{l}\text { Used oral corticosteroid } \\
\text { therapyt }\end{array}$ & 50 & 55 & 59 & 60 \\
\hline \multicolumn{5}{|l|}{ Yes, $\%$} \\
\hline Visited orthopedic surgeon $†$ & 23 & 33 & 39 & 42 \\
\hline \multicolumn{5}{|l|}{ Yes, \% } \\
\hline No. of visits, mean (SD) & $3.2(2.5)$ & $4.0(3.3)$ & $4.6(4.1)$ & $5.4(4.9)$ \\
\hline \multicolumn{5}{|l|}{$\begin{array}{l}\text { Underwent orthopedic } \\
\text { surgery } \\
\text { for rheumatoid arthritis } †\end{array}$} \\
\hline Yes, \% & 6 & 12 & 15 & 19 \\
\hline $\begin{array}{l}\text { No. of operations, mean } \\
\text { (SD) }\end{array}$ & $1.4(1.1)$ & $1.5(1.1)$ & $1.8(1.2)$ & $1.9(1.6)$ \\
\hline
\end{tabular}

Note: $\mathrm{SD}=$ standard deviation, DMARD = disease-modifying anti-rheumatic drug.

*The number of patients differs each year because the annual totals represent the patients who reached the maximum co-payment amount that year.

†Since 1996. billing data collected by the Ministry of Health of British Columbia to facilitate reimbursement for physician visits was used to identify all existing cases of rheumatoid arthritis treated between January 1996 and December 2000. For each patient, data on the use of all provincially funded health care resources, including hospital care, physician visits and prescribed medications dispensed by pharmacists, were obtained. Details of this cohort are described elsewhere. ${ }^{10}$ From the cohort data, we determined that the prevalence of rheumatoid arthritis in the $\mathrm{BC}$ population was $0.76 \%$, which is consistent with prevalence rates of $0.5 \%$ to $\mathrm{I} . \mathrm{I} \%$ (mean $0.8 \%$ ) reported in epidemiologic studies of the condition. ${ }^{11}$

BC PharmaCare is British Columbia's drug benefit plan that assists provincial residents in paying for eligible prescription drugs and designated medical supplies. The plan provides residents different levels of coverage. At the time of the study, BC PharmaCare required that people aged 65 years and older pay $100 \%$ of the dispensing fees, but not the ingredient costs, to an annual maximum of \$200. Once this deductible was reached, the drug benefit plan covered all dispensing fees and ingredient costs of drugs on the provincial formulary for the remainder of the year. PharmaCare has a Maximum Days Supply Policy to prevent wastage and stockpiling. For short-term or first-time drug prescriptions of maintenance drugs, the coverage is limited to a maximum 30-day supply, whereas repeat prescriptions of maintenance drugs are covered for a maximum Iooday supply.

For this study we selected elderly patients from the population-based cohort described earlier who had existing rheumatoid arthritis (diagnosed in the previous year or earlier) and who had reached the annual maximum co-payment of \$200 for any calendar year from 1997 to 2000. For each patient selected, we included in the analysis only data for health care services used during the year(s) in which the annual maximum co-payment had been reached. Since the sample was selected on the basis of annual drug prescription records and the year rheumatoid arthritis was first diagnosed, the number of patients being selected differed from year to year.

The outcomes assessed were whether patients were admitted to hospital, the number of hospital admissions, the number of physician visits and the total number of prescriptions filled. All of these outcomes were measured for all care received.

We assessed the following variables for rheumatoid arthritis care as covariates: whether patients had been prescribed disease-modifying antirheumatic drugs (DMARDs), an important part of the medical treatment of rheumatoid 
arthritis; how long patients had the condition; whether patients were prescribed oral corticosteroid therapy during the study period; whether and how often patients visited an orthopedic surgeon; whether they had undergone orthopedic surgery; and the number of orthopedic procedures performed for rheumatoid arthritis.

For statistical analysis, we defined the period during which the annual maximum co-payment had not been reached as the "cost-sharing period" and the one beyond which the annual maximum had been reached as the "free period." For each of the calendar years from 1997 to 2000 , we compared the patients' utilization of all health care services between the cost-sharing and free periods.

For our analysis of the use of hospital services, we used a 2-part model. First, we compared the probability of a patient being admitted to hospital during the cost-sharing period with that of admission during the free period. For this analysis we used an estimated logistic regression analysis folowing the generalized estimating equations (GEE) approach (with an unstructured correlation matrix). ${ }^{12}$ Second, we studied the number of hospital admissions in a given year among the patients who were admitted during the year. To adjust for the different lengths of the cost-sharing and free periods, we used monthly figures. A paired sample comparison was performed for each year to assess the difference in monthly utilization of hospital services. The $95 \%$ confidence interval for each of the mean differences was estimated through bootstrap sampling. We also fitted a mixed-effect model with a random patient effect and fixed effects of period and year and other explanatory variables (e.g., age, sex, DMARD use, corticosteroid use, visits with an orthopedic surgeon and performance of orthopedic surgery). The covariate values were evaluated based on data since the beginning of 1996 to the end of the year before which the outcomes were evaluated. Utilization in a particular year, the dependent variable, was modelled to be dependent on covariates from the previous years except for the dummy variable indicating the cost-sharing period and the free period; therefore, utilization was based on data from 1997 to 2000 , but covariates were evaluated using data from 1996 to 2000. Explanatory variables were retained in the final model if $p$ values for the $\beta$ coefficients were less than 0.05 .

We performed similar analyses on all outcomes, including the number of physician visits per month, the number of pre- scriptions filled per month and the number of prescriptions filled per physician visit.

\section{Results}

A total of Io 735 elderly people had existing rheumatoid arthritis; about $18 \%-20 \%$ of them reached the annual maximum co-payment. We selected for our study 2968 unique patients: $18 \%$ reached the annual maximum co-payment in all of the 4 years studied; $16 \%, 24 \%$ and $43 \%$ did so for 3,2 and I of the years, respectively. Table I shows the patients' characteristics at the beginning of each year. The mean age of the patients was about 74 (standard deviation 6) years, and $75 \%-$ $78 \%$ were women. In $1997,45 \%$ of the patients had been prescribed a DMARD at least once January 1996 . This proportion gradually increased to $49 \%$ of patients in 2000 . The annual use of oral corticosteroid therapy varied from $50 \%$ to $60 \%$ during the study period.

The annual utilization of hospital services, physician services and prescription drugs are summarized in Table 2. About $54 \%$ of the patients were admitted to hospital at least once each year. Patients who were admitted had on average 2 hospital admissions per year. The mean number of physician visits was about 32 per year, and the mean number of prescriptions filled ranged from about 49 to 56 . The average dispensing fee per prescription was $\$ 7.50$, and it took a patient about $8^{1} / 2$ months to reach the annual maximum co-payment of $\$ 200$.

Table 3 shows the utilization rates during the cost-sharing and free periods. Overall, the proportion of patients with at least one hospital admission during the cost-sharing period was consistently higher than the proportion during the free period over the 4 years. However, the cost-sharing period was about twice as long as the free period (8.5 v. 3.5 months). The number of admissions per month was higher during the costsharing period than during the free period except in 2000; the differences were not statistically significant except in 1997. When we compared the number of physician visits per month during the 2 periods, we found that patients used significantly more physician services during the cost-sharing period than during the free period over the 4 years. When looking at the number of prescriptions filled per month, we found that fewer were filled during the cost-sharing period than during the free period. Similarly, patients had fewer prescriptions filled per physician visit during the cost-sharing period.

\begin{tabular}{|c|c|c|c|c|}
\hline Variable & $\begin{array}{c}1997 \\
n=1191\end{array}$ & $\begin{array}{c}1998 \\
n=1428\end{array}$ & $\begin{array}{c}1999 \\
n=1702\end{array}$ & $\begin{array}{c}2000 \\
n=1882\end{array}$ \\
\hline Cost-sharing period, mean (SD), mo & $8.6(2.3)$ & $8.5(2.4)$ & $8.3(2.5)$ & $8.2(2.6)$ \\
\hline$\%$ of patients admitted to hospital & 55 & 53 & 55 & 54 \\
\hline No. of hospital admissions, mean (SD) & $1.98(1.40)$ & $2.10(1.96)$ & $1.98(1.38)$ & $2.00(1.46)$ \\
\hline No. of physician visits, mean (SD) & $32.2(18.4)$ & $31.9(20.4)$ & $32.8(20.5)$ & $31.8(20.0)$ \\
\hline No. of prescriptions filled, mean (SD) & $48.7(23.7)$ & $50.2(28.6)$ & $53.0(38.6)$ & $56.2(47.0)$ \\
\hline
\end{tabular}

Note: $\mathrm{SD}=$ standard deviation . 
Table 3: Annual utilization of health care services by drug-coverage period*

\begin{tabular}{|c|c|c|c|c|}
\hline Variable; period & 1997 & 1998 & 1999 & 2000 \\
\hline \multicolumn{5}{|l|}{ Hospital services } \\
\hline $\begin{array}{l}\text { No. }(\%) \text { of patients admitted } \\
\text { to hospital }\end{array}$ & $651(55)$ & $757(53)$ & 939 (55) & $1007(54)$ \\
\hline $\begin{array}{l}\% \text { of patients admitted during } \\
\text { cost-sharing period }\end{array}$ & 45 & 44 & 43 & 40 \\
\hline $\begin{array}{l}\% \text { of patients admitted during } \\
\text { free period }\end{array}$ & 22 & 22 & 25 & 25 \\
\hline \multicolumn{5}{|l|}{$\begin{array}{l}\text { Hospital admissions per month, } \dagger \\
\text { mean no. (SD) }\end{array}$} \\
\hline Cost-sharing period & $0.17(0.18)$ & $0.18(0.21)$ & $0.17(0.19)$ & $0.16(0.18)$ \\
\hline Free period & $0.14(0.24)$ & $0.17(0.36)$ & $0.16(0.26)$ & $0.17(0.30)$ \\
\hline Difference $(95 \% \mathrm{Cl})$ & $0.04(0.01$ to 0.06$)$ & $0.02(-0.01$ to 0.05$)$ & $0.02(-0.004$ to 0.04$)$ & $-0.007(-0.03$ to 0.01$)$ \\
\hline \multicolumn{5}{|l|}{ Physician visits } \\
\hline \multicolumn{5}{|l|}{$\begin{array}{l}\text { Physician visits per month, } \\
\text { mean no. (SD) }\end{array}$} \\
\hline Cost-sharing period & $2.8(1.8)$ & $2.8(1.9)$ & $2.8(2.0)$ & $2.8(1.9)$ \\
\hline Free period & $2.4(2.2)$ & $2.4(2.4)$ & $2.5(2.4)$ & $2.4(2.2)$ \\
\hline Difference $(95 \% \mathrm{Cl})$ & $0.45(0.32$ to 0.57$)$ & 0.40 (0.28 to 0.52$)$ & 0.29 (0.17 to 0.41$)$ & 0.41 (0.31 to 0.51$)$ \\
\hline \multicolumn{5}{|l|}{ Prescriptions filled } \\
\hline \multicolumn{5}{|l|}{$\begin{array}{l}\text { Prescriptions filled per month, } \\
\text { mean no. (SD) }\end{array}$} \\
\hline Cost-sharing period & $4.0(1.9)$ & $4.1(2.1)$ & $4.3(2.8)$ & $4.6(3.8)$ \\
\hline Free period & $4.3(3.1)$ & $4.7(5.3)$ & $4.8(4.7)$ & $5.2(5.7)$ \\
\hline Difference & $-0.23(-0.39$ to -0.07$)$ & $-0.61(-0.87$ to 0.35$)$ & $-0.43(-0.63$ to -0.24$)$ & $-0.65(-0.87$ to 0.44$)$ \\
\hline \multicolumn{5}{|l|}{$\begin{array}{l}\text { Prescriptions filled per physician } \\
\text { visit, mean no. (SD) }\end{array}$} \\
\hline Cost-sharing period & $2.1(2.4)$ & $2.3(2.8)$ & $2.5(3.1)$ & $2.6(3.4)$ \\
\hline Free period & $2.5(2.8)$ & $2.8(3.5)$ & $2.7(4.7)$ & $3.3(6.7)$ \\
\hline Difference & $-0.39(-0.56$ to -0.22$)$ & $-0.48(-0.63$ to -0.33$)$ & $-0.24(-0.40$ to -0.08$)$ & $-0.66(-0.94$ to -0.37$)$ \\
\hline
\end{tabular}

Note: $\mathrm{SD}=$ standard deviation, $\mathrm{Cl}$ = confidence interval.

${ }^{*}$ Cost-sharing period $=$ period during which patients had not reached the annual maximum deductible of $\$ 200$ to pay for dispensing fees; free period = period beyond which the annual maximum deductible had been reached.

†Among patients who were admitted to hospital at least once during the year.

The results from the multivariate analysis are shown in Table 4. The estimated logistic regression model revealed that the probability of being admitted to hospital did not differ between the cost-sharing and free periods after adjustment for the duration of each period and for other covariates, including age, sex, corticosteroid use, visit to an orthopedic surgeon and year. Among the patients who were admitted to hospital, the adjusted mean difference between the cost-sharing period and the free period in the number of admissions per month was small but was statistically significant. The adjusted mean differences between the 2 periods in the number of physician visits and the number of prescriptions filled were statistically significant, with more patients seeing physicians per month and fewer having prescriptions filled per month and per physician visit during the cost-sharing period than during the free period.

To ensure that our results were not confounded by sea- sonal variations, we looked at utilization per month of hospital services, physician services and prescription drugs during I997 and 2000 among patients receiving social assistance. These patients are fully covered by the PharmaCare program and their utilization patterns would therefore not be expected to be affected by the co-payment policy. We found no significant seasonal effects.

\section{Interpretation}

Health services researchers have been examining the effect of patient cost-sharing for more than 20 years. Costs can be shared for office visits, emergency department use and prescription drugs, among other things. In our study, we focused on the effect of cost-sharing of prescription drugs on overall health care utilization among elderly patients with existing rheumatoid arthritis. We found that these patients 
Table 4: Adjusted mean difference between cost-sharing period and free period by outcome*

\begin{tabular}{|c|c|}
\hline Outcome & $\begin{array}{l}\text { Adjusted mean difference } \\
\text { between periods } \dagger(95 \% \mathrm{Cl})\end{array}$ \\
\hline Admission to hospitalf & OR $0.99(0.90,1.11)$ \\
\hline $\begin{array}{l}\text { Frequency of hospital admissions } \\
\text { per month§ }\end{array}$ & $0.013(0.002$ to 0.025$)$ \\
\hline $\begin{array}{l}\text { Frequency of physician visits } \\
\text { per month }\end{array}$ & $0.38(0.32$ to 0.44$)$ \\
\hline $\begin{array}{l}\text { Frequency of prescriptions filled } \\
\text { per month** }\end{array}$ & $-0.50(-0.61$ to -0.38$)$ \\
\hline $\begin{array}{l}\text { Frequency of prescriptions filled } \\
\text { per physician visit†† }\end{array}$ & $-0.52(-0.64$ to -0.40$)$ \\
\hline
\end{tabular}

Note: $\mathrm{OR}=$ odds ratio, $\mathrm{Cl}=$ confidence interval.

*See Table 3 footnote for definition of periods.

†Unless specified otherwise.

$\ddagger$ Adjusted for age, sex, corticosteroid use (yes/no), visit to orthopedic surgeon (yes/no) and year.

§Among those admitted to hospital at least once during the year; adjusted for sex and corticosteroid use (yes/no).

१Adjusted for sex, corticosteroid use (yes/no), visit to orthopedic surgeon (yes/no), duration of rheumatoid arthritis and year.

${ }^{* *}$ Adjusted for age, corticosteroid use (yes/no) and year.

††Adjusted for age, sex, corticosteroid use (yes/no), visit to orthopedic surgeon (yes/no) and year.

had fewer prescriptions filled but used more physician services during the period when they had to pay the dispensing fees for prescription drugs than during the period when all drug costs were covered. Although the odds of being admitted to hospital did not differ between the 2 periods, patients who were admitted to hospital were admitted more frequently per month during the cost-sharing period. The fact that patient co-payment of prescription drugs was more strongly associated with a reduction in medication use and an increase in physician visits but less strongly associated with an increase in hospital admissions may have been because the first 2 forms of utilization are more under the control and choice of patients than is hospital admission.

Our findings suggest that prescription drugs and other health care services are economic substitutes. Other recent studies both contradict and support our findings. ${ }^{6,13} \mathrm{Al}-$ though Escarce and colleagues ${ }^{6}$ found that prescription drug cost-sharing in US settings was associated with a reduction in expenditures for prescription drugs, as was observed in our study, they found that cost-sharing was associated with reductions in physician services and hospital services as well. They therefore concluded that prescription drugs and these services were economic complements. Tamblyn and colleagues, ${ }^{13}$ on the other hand, observed that, after the introduction in 1996 of a co-payment policy for prescription drugs for elderly people in Quebec, there was an increase in the frequency of hospital, emergency department and doctor visits, along with a reduction in the use of prescription drugs. Given that the latter study was based in Canada, their results and ours are probably more representative of the Canadian setting.
Some potential limitations of our study should be noted. The one limitation shared by all studies using administrative data for the identification of cases is the uncertainty around the accuracy of the diagnosis. ${ }^{10}$ Another potential limitation is the presence of supplemental insurance. However, since patients with supplemental insurance would have had it in both periods, we did not expect this factor to be a confounder. Similarly, patients may have used alternative medicines or alternative health care services as a substitute to prescription drugs, which we would have been unable to capture from the administrative data. In addition, we did not have direct measures of disease severity; instead, we used duration of rheumatoid arthritis, use of DMARDs, use of oral corticosteroid therapy, visits to an orthopedic surgeon and orthopedic surgeries performed for rheumatoid arthritis as indicators of disease severity.

Our findings indicate that physician visits and hospital services are economic substitutes for prescription drugs: during the period when patients have to pay part of all of their drug costs, the frequency of doctor visits and hospital admissions increases. Our results show that, in a predominantly publicly funded health care system, the implementation of piecemeal cost-containment strategies such as cost-sharing of prescription drugs might have the unintended effect of increasing overall health care utilization. As health system reform is being contemplated in Canada, and indeed worldwide, it may be wise to evaluate a policy that would apply to the whole system - first-dollar coverage for all services or cost-sharing for all services - as opposed to a hybrid or mixed policy.

This article has been peer reviewed.

From the Department of Health Care and Epidemiology (Anis, Rashidi, Li), the Division of Rheumatology (Lacaille, Esdaile) and the Faculty of Pharmaceutical Sciences (Marra), University of British Columbia; the Centre for Health Evaluation and Outcome Sciences (Anis, Guh, Rashidi, Li), St. Paul's Hospital; and the Arthritis Research Centre of Canada (Anis, Lacaille, Marra, Esdaile), Vancouver, BC

Competing interests: None declared.

Contributors: Aslam Anis, Daphne Guh, Carlo Marra and Amir Rashidi contributed substantially to the study conception and design. Aslam Anis, Diane Lacaille and John Esdaile contributed to the acquisition, analysis and interpretation of the data. Daphne Guh and Xin Li contributed to the analysis and interpretation of the data. All of the authors helped draft the manuscript and revised it for critical content.

Acknowledgements: We thank Dianne Calbick for her research and administrative assistance.

This project was supported by the Canadian Institutes of Health Research and the Canadian Arthritis Network.

\section{REFERENCES}

I. Keeler EB, Rolph JE. How cost sharing reduced medical spending of participants in the health insurance experiment. JAMA I983;249(I6):2220-7.

2. Newhouse JP, Manning WG, Morris CN, et al. Some interim results from a controlled trial of cost sharing in health insurance. N Engl J Med I98I;305(25):I50I-7.

3. Keeler EB. Effects of cost sharing on use of medical services and health. J Med Practice Manage i992;8(I):II-5.

4. Shapiro MF, Ware JE Jr, Sherbourne CD. Effects of cost sharing on seeking care for 
serious and minor symptoms. Results of a randomized controlled trial. Ann Intern Med Ig86;I04(2):246-5I.

5. Joyce GF, Escarce JJ, Solomon MD, et al. Employer drug benefit plans and spending on prescription drugs [published erratum in JAMA 2002;288(19):2409]. JAMA 2002;288(I4):1733-9.

6. Escarce JJ, Kapur K, Joyce GF, Van Vorst KA. Medical care expenditures under gatekeeper and point-of-service arrangements. Health Serv Res 2001;36(6):1037-57.

7. Joyce GF, Kapur K, Van Vorst KA, et al. Visits to primary care physicians and to specialists under gatekeeper and point-of-service arrangements. Am J Managed Care 2000;6(II):II89-96.

8. Kapur K, Joyce GF, Van Vorst KA, et al. Expenditures for physician services under alternative models of managed care. Med Care Res Rev 2000;57(2):I6I-8I.

9. Anis AH, Guh D, Wang X. A dog's breakfast: prescription drug coverage varies widely across Canada. Med Care 2001;39:315-326.

Io. Lacaille D, Anis AH, Guh D, et al. Gaps in care for the rheumatoid arthritis: a population study. Arthritis Rheum 2005;53(2):24I-8.

II. Silman A, Hochberg MC. Rheumatoid arthritis. In: Silman A, Hochberg MC, editors. Epidemiology of the rheumatic diseases. Oxford (UK): Oxford Press; I993. p. 7-68.

I2. Liang KY, Zeger SL. Longitudinal data analysis using generalized linear models. Biometrika I986;73(I):13-22.

13. Tamblyn R, Laprise R, Hanley JA, et al. Adverse events associated with prescription drug cost-sharing among poor and elderly persons. JAMA 200I;285(4):42I-9.

Correspondence to: Dr. Aslam H. Anis, Centre for Health Evaluation and Outcome Sciences, St. Paul's Hospital, 620-I08I Burrard St., Vancouver BC V6Z IY6; fax 604 806-8778; aslam.anis@ubc.ca

\section{Editor's take}

- Many universal health insurance plans, including Canada's, do not fully cover the costs of prescription drugs. Does this limited coverage have unintended effects on how patients use health care services?

- In this study, elderly patients with rheumatoid arthritis, a severe joint disease requiring ongoing drug therapy, were included if they reached the maximum annual co-payment for prescription drugs, after which drugs are "free" for the remainder of the year. Data were collected on the frequency of hospital admissions, physician visits and prescription filling during the cost-sharing period and the "free" period.

- Patients had more hospital admissions and visits to physicians and filled fewer prescriptions per month during the cost-sharing period than during the free period.

Clinical implications: This study provides good evidence that cost-sharing of prescription drugs results in fewer prescriptions being filled and more physician visits and hospital admissions. 